\title{
Comparative study between (Dexamethasone - Bupivacaine) versus (Magnesium sulfate - Bupivacaine) for postoperative analgesia
}

\author{
Ahmad EL-Saied Abdel Rahman Ali*; Mohammed Abdel Rehem \\ Mohammed**;Ahmed Hamody Hassan***and Haitham Sayed Mohammed*****
}

\begin{abstract}
- Aim: This work aims to compare the postoperative analgesic effects and side effects of Dexamethasone or Magnesium sulfate $(\mathrm{Mg})$ that added to bupivacaine.
\end{abstract}

- Patient and Methods: Eighty patients aged between 16-70 years with ASA I- II who were scheduled for infra-umbilical surgeries under spinal anesthesia were enrolled in our study after written informed consent and approval of ethical committee; This Study was conducted in Sohag University Hospitals from August 2016 to March 2017. Patients Were divided into 2 equal groups:- (Group A) 40 patients received 50mg magnesium sulphate added to $2.5 \mathrm{ml}$ volume of $0.5 \%$ hyperbaric bupivacaine plus $0.5 \mathrm{ml}$ Normal saline.(Group B) 40 patients received $4 \mathrm{mg}$ dexamethasone added to $2.5 \mathrm{ml}$ volume of $0.5 \%$ hyperbaric bupivacaine. Under complete aseptic conditions, spinal anesthesia was carried out in the sitting position, at level (L2-3 or L3-4). After a free flow of cerebrospinal fluid was confirmed, each patient received one of the coded spinal solutions (GA or GB).Immediately after administration; the patients were turned into the supine position. Patients were monitored for: Heart rate; NIBP and Oxygen Saturation. Patients were observed for onset, duration of sensory block and motor block; In the post-anesthesia care unit (PACU), the patients were asked to assess their level of pain based on a visual analog scale (VAS). Complications also were observed .

- Results: Dexamethasone had a faster Onset of sensory block onset than Magnesium Sulphate; Dexamethasone had a longer duration of regard Duration of motor block than Magnesium Sulphate; Magnesium Sulphate group had a longer analgesic effect stayed longer than Dexamethasone group .No Significant difference Between Two groups in rate of Complications ; Hypotension and Bradycardia were the most frequent complications in the two groups .Conclusion: the addition of Dexamethasone $4 \mathrm{mg}$ or Magnesium Sulphate $50 \mathrm{mg}$ to intrathecallv iniected Bupivacaine improved the effect of

\section{Introduction}

-Spinal Anesthesia is the most commonly used technique for lower abdominal surgeries as it is very economical and easy to administer. (1).
-Spinal anesthesia has the advantage that profound nerve block can be produced in a large part of the body by the relatively simple injection of a small amount of 
local anesthetic (6).

-Spinal anesthesia avoids the risks of general anesthesia such as aspiration of gastric contents and difficulty with airway management. (1).

-However, postoperative pain control is a major problem because spinal anesthesia using only local anesthetics associated with relatively short duration of action, and thus early analgesic intervention is needed in the postoperative period ( 3 ). .

-To improve the quality of central neuraxial block or spinal anesthesia, adjuvant drugs are used with local anesthetics. These drugs enhance or potentiate the actions of local anesthetics in order to improve the latency of the block, duration, and quality of analgesia. (1).

-Opioids that are added intrathecally prolong the duration of anesthesia, but are associated with a number of undesirable side e ects like delayed respiratory depression, urinary retention, pruritis, nausea, and vomiting. . (1).

-Drugs like dexmedetomidine, dexamethasone and magnesium sulfate have also been used successfully as an adjunct in spinal anesthesia along with local anesthetic (5).

-It is known that Dexamethasone has anti-inflammatory and analgesic action by inhibition of transmission in nociceptive C-fibers and neural discharge. When given as an additive in peripheral nerve blocks or in intrathecal anesthesia, it prolongs the duration of anesthesia. (1).

-Magnesium sulfate (Mg) improves postoperative analgesia after intrathecal administration as an effective adjuvant to bupivacaine by inhibits calcium entry into cells also involved in decreased catecholasmine release associated with sympathetic nerve stimulation during pain episode. . (7).

\section{Patients and Methods}

Eighty patients aged between 16-70 years with ASA I- II who were scheduled for infra-umbilical surgeries under spinal anesthesia were enrolled in our study after written informed consent and approval of ethical committee.This Study was conducted in Sohag University Hospitals from August 2016 to March 2017.Patientswere excluded if they had a history of Opium addiction, sedative drugs consumption; Contraindication for spinal anesthesia, as sepsis, severe coagulopathy and severe heart disease.; Patient with long history of steroid use or Patient unable to communicate making postoperative assessment di cult.

Patients were divided into 2 equal groups:

- (Group A) 40 patients received 50mg magnesium sulphate added to $2.5 \mathrm{ml}$ volume of $0.5 \%$ hyperbaric bupivacaine plus $0.5 \mathrm{ml}$ Normal saline.

- (Group B) 40 patients received 4mg dexamethasone added to $2.5 \mathrm{ml}$ volume of $0.5 \%$ hyperbaric bupivacaine.

Then we did the followings:

1- A venous access was secured using wide bore cannula and the patient was preloaded with lactated ringer solution $(10 \mathrm{ml} / \mathrm{kg})$ before the induction of the spinal anesthesia

2- Under complete aseptic conditions, spinal anesthesia was carried out in the sitting position, at level (L2-3 or L3-4). After a free flow of cerebrospinal fluid was confirmed, each patient received one of the coded spinal solutions (GA or GB).

3- Immediately after administration, the patients were turned into the supine position 
4- Patients were monitored by:_Heart rate using ECG electrodes; NIBP Using NIBP Cable and Oxygen Saturation Using Pulse Oximetery. And baseline values were recorded.

5- Observations:

A-Patients were observed for onset, duration of sensory block bilaterally by using to pin prick with a short hypodermic needle

B- Motor blockade is assessed based on a modified Bromage scale:

, $\quad$ Grade 0 no paralysis, able to flex extended leg at hip;

- Grade 1 able to flex knee but not flex extended leg;

Grade 2 able to move foot only;

Grade 3 unable to move foot (Biswas et al; 2002)

These tests were performed every $5 \mathrm{~min}$ after the spinal block intra-operative and every 15 minutes postoperative for 3 hours until the sensory and motor variables were back to normal.

C- Intra operatively, the patients received $10 \mathrm{~mL} / \mathrm{Kg}$ lactated Ringer solution.Systolic ;Diastolic Blood Pressure and Heart rate were recorded before spinal anesthesia and there after every $5 \mathrm{~min}$ until the end of the procedure and every 15 minutes for 3 hours

D- Oxygen Saturation were recorded before spinal anesthesia and there after every $5 \mathrm{~min}$ until the end of the procedure
E- In the post-anesthesia care unit (PACU), the patients were asked to assess their level of pain based on a visual analog scale (VAS) ranging from 0 (no pain) to 10 (maximal pain) every 15 minutes for 3 hours.

Visual Analogue Score (VAS): The VAS is validated approach to pain measurement; it consists of a $10-\mathrm{cm}$ line with one end labeled "no pain" and the other end labeled "worst pain imaginable." The patient marks the line at the point that best describes the pain intensity (Jensen 1993)

F- Complications:

Nausea, vomiting, pruritus, shivering, desaturation or hypoxemia $(\mathrm{SpO} 2$ $<90 \%$ ), respiratory depression (RR < $10)$, bradycardia and hypotension were also noticed and treated accordingly.

\section{Statistical analysis}

Data was analyzed using STATA intercooled version 12.1. Quantitative data was represented as mean, standard deviation, median and range. Data was analyzed using student t-test to compare means of two groups. When the data was not normally distributed Mann-Whitney test was used. Qualitative data was presented as number and percentage and compared using either Chi square test or fisher exact test. Graphs were produced by using Excel or STATA program. P value was considered significant if it was less than 0.05 .

\section{Results}

There was No Statistically significant difference between dexamethasone group and Magnesium sulfate group as regard age or sex of patients

There was statistically significant difference between dexamethasone group and Magnesium sulfate group as regard Onset of sensory block as (P value Significant when $<0.05)$.As Dexamethasone group has faster onset of sensory block.; There was statistically significant difference between dexamethasone group and Magnesium sulfate group as regard as Duration of motor block as Dexamethasone group has longer duration of motor block; There was statistically significant difference between dexamethasone group and Magnesium sulfate group as regard Time to first analgesia as Magnesium 
Sulfate group took more time for first analgesia.; There was statistically significant difference between dexamethasone group and Magnesium sulfate group as regard Duration of Surgery as Surgery in Dexamethasone group take a longer time; There was no statistically significant difference between dexamethasone group and Magnesium sulfate group as regard Onset of motor block; There was no statistically significant difference between dexamethasone group and Magnesium sulfate group as regard Duration of Sensory Block.(tabale1)

\begin{tabular}{|c|c|c|c|}
\hline Variable & $\begin{array}{c}\text { Dexamethasone } \\
\text { group }\end{array}$ & Magnesium sulfate group & P value \\
\hline $\begin{array}{l}\text { Onset of sensory block } \\
\text { M ean } \pm \text { SD } \\
\text { M edian (range) }\end{array}$ & $\begin{array}{c}2.65 \pm 0.77 \\
3(1-4)\end{array}$ & $\begin{array}{c}3.08 \pm 0.73 \\
3(1-4)\end{array}$ & 0.01 \\
\hline $\begin{array}{l}\text { Onset of motor block } \\
\text { Mean } \pm \text { SD } \\
\text { Median (range) }\end{array}$ & $\begin{array}{c}4.03 \pm 0.80 \\
4(2-5)\end{array}$ & $\begin{array}{c}4.2 \pm 0.69 \\
4(2-5)\end{array}$ & 0.29 \\
\hline $\begin{array}{l}\text { Duration of surgery } \\
\text { M ean } \pm \mathrm{SD} \\
\text { M edian (range) }\end{array}$ & $\begin{array}{c}52.65 \pm 20.81 \\
50(20-105)\end{array}$ & $\begin{array}{c}43.5 \pm 13.45 \\
47.5(15-65)\end{array}$ & 0.02 \\
\hline $\begin{array}{l}\text { Duration of sensory block } \\
\text { M ean } \pm \text { SD } \\
\text { M edian (range) }\end{array}$ & $\begin{array}{l}149.25 \pm 11.28 \\
151(115-165)\end{array}$ & $\begin{array}{c}148.95 \pm 5.28 \\
150(130-155)\end{array}$ & 0.88 \\
\hline $\begin{array}{l}\text { Duration of motor block } \\
\text { M ean } \pm \text { SD } \\
\text { M edian (range) }\end{array}$ & $\begin{array}{c}140.9 \pm 12.84 \\
140(120-165)\end{array}$ & $\begin{array}{c}135 \pm 5.54 \\
135(120-145)\end{array}$ & 0.009 \\
\hline $\begin{array}{l}\text { Time to first analgesia } \\
\text { M ean } \pm \text { SD } \\
\text { M edian (range) }\end{array}$ & $\begin{array}{l}186.58 \pm 24.45 \\
180(145-240)\end{array}$ & $\begin{array}{l}198.25 \pm 14.17 \\
200(165-215)\end{array}$ & 0.01 \\
\hline $\begin{array}{l}\text { Comparison between } \\
\text { regard analgesic effe }\end{array}$ & $\begin{array}{l}\text { methasone group a } \\
\text { duration of surger }\end{array}$ & $\begin{array}{l}\text { Tagnesium sulfate group as } \\
\text { le nol }\end{array}$ & \\
\hline
\end{tabular}

There was NO statistically significant difference between dexamethasone group and Magnesium sulfate group as regard heart rate or oxygen saturation;As regard Systolic and Diastolic Blood pressure; Intraoperative there was Statistically Significant difference only in first 20 minutes then there was no Statistically Significant difference; Postoperative there was only Statistically Significant difference only in last 20 minutes. As regard Complication that No Significant difference Between Two groups in rate of Complications; Hypotension and Bradycardia were most frequent complications in the two groups (graph.1)

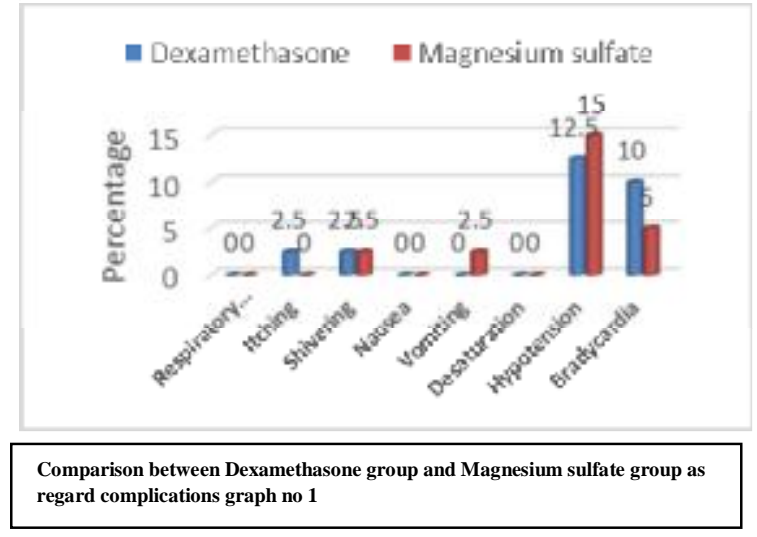




\section{Discussion}

In our Study there was statistically significant difference between dexamethasone group and Magnesium sulfate group as regard Onset of sensory block ; as it was faster in Dexamethasone group) $2.65 \pm .77 \mathrm{~min}$ ) while it was $(3.08 \pm .73 \mathrm{~min})$ in Magnesium Sulfate group with Noticeable statistically Significant difference $\mathrm{P}$ value $(0.01)$

Also; In our Study there was no statistically significant difference between dexamethasone group and Magnesium sulfate group as regard Onset of motor block; as it was mildly faster in dexamethasone group $(4.03 \pm 0.80 \mathrm{~min})$ while it was $(4.2 \pm 0.69$ min) in Magnesium Sulfate group with No Significant statistically difference.

In agreement to our study as regard Magnesium Sulfate group Nair et al 2103 in their study (Clinical effects of intrathecal midazolam versus intrathecal magnesium sulfate as adjunct to hyperbaric bupivacaine) Said that Onset of sensory block was longer in Magnesium Sulfate group (5.96 \pm 0.958 min) and also onset of Motor block in Magnesium Sulfate group was longer( $8.323 \pm 1.388 \mathrm{~min}$.

In contrast to our study Elzayyat; et al;2014 in their study (Comparing the effect of adding

dexmedetomidine versus dexamethasone on prolonging the duration of intrathecal bupivacaine in lower abdominal operations); Said that the onset of sensory block was longer in dexamethasone group $(3.3 \pm 2.0 \mathrm{~min})$ and also onset of Motor block was longer in dexamethasone group (4.2 \pm $3.2 \mathrm{~min}$ ).

In Our Study there was statistically significant difference between dexamethasone group and Magnesium sulfate group as Regard Duration of motor block was longer in dexamethasone group $(140.9 \pm 12.84)$ while it was $(135 \pm 5.54)$ in magnesium sulfate group with Noticeable statistically Significant difference $P$ value (0.009).

In agreement to our study ; Elzayyat; et al2014 in their study (Comparing the effect of adding dexmedetomidine versus dexamethasone on prolonging the duration of intrathecal bupivacaine in lower abdominal operations); Said that duration of motor block in Dexamthasone study was longer $(157.3 \pm 30.2 \mathrm{~min})$.

In contrast to our study; Janghorbani et al 2011 in their study (Effects of adjunct intrathecal magnesium sulfate to bupivacaine for spinal anesthesia); found that duration of motor block in Magnesium sulphate group was shorter (120 $\pm 133 \mathrm{~min})$.

Also we found that; In Our Study there was statistically significant difference between dexamethasone group and Magnesium sulfate group as regard Time to first analgesia (Duration of analgesia) was longer in magnesium Sulfate $(198.25 \pm 14.17 \mathrm{~min})$ while it was $(186.58 \pm 24.45 \mathrm{~min})$ in Dexamethasone group with Noticeable statistically Significant difference $\mathrm{P}$ value (0.01).

In agreement to our study; Elzayyat; et al2014 in their study (Comparing the effect of adding dexmedetomidine versus dexamethasone on prolonging the duration of intrathecal bupivacaine in lower abdominal operations); Said that Time to first analgesic given to patients in dexamethasone group was shorter $(2.80$ \pm 0.86 hour)

In agreement to our study; Hefni et al 2014 in their study (Epidural dexamethasone for postoperative analgesia in patients 
undergoing abdominal hysterectomy); found that time for first analgesia in patients received $4 \mathrm{mg}$ dexamethasone in epidural space was longer $(3.50 \pm 3.0 \mathrm{~h})$; in patients received $6 \mathrm{mg}$ dexamethasone was also longer $(3.75 \pm 5.0 \mathrm{~h})$ and in patients received $8 \mathrm{mg}$ dexamethasone was also longer $(5.04 \pm 6.08 \mathrm{~h})$.

In contrast to our study; Bani-Hashem et al 2011in their study (Addition of intrathecal Dexamethasone to Bupivacaine for spinal anesthesia in orthopedic surgery); claimed that duration of pain free period in patients received intrathecal dexamethasone was longer (401.92 $\pm 72.64 \mathrm{~min}$ ).

In agreement to our study; Nair et al 2103 in their study (Clinical effects of intrathecal midazolam versus intrathecal magnesium sulfate as adjunct to hyperbaric bupivacaine) said that analgesia time in his study in Magnesium sulfate group was longer $(206.45 \pm 26.24 \mathrm{~min})$.

In contrast to our study; Regar et al 2017 in their study (A Comparative study of intrathecal Dexmedetomidine with intrathecal Magnesium Sulfate used as adjuvant to Bupivacaine); said hat duration of analgesia in Magnesium sulphate group was longer (304.40+80.88 min).

Our Study showed that No Significant difference Between Two groups in rate of Complications and Showed that Hypotension was more Frequent Complication Followed by Bradycardia as follow:

Dexamethasone group:Hypotension 5 cases $(12.50 \%)$.......Bradycardia 4 cases $(10.00 \%)$... Itching 1 case $\quad(2.50 \%)$ .....Shivering 1case $(2.50 \%)$

Magnesium sulfate group:Hypotension 6 cases $(15.00 \%)$......Bradycardia 2 cases $(5.00 \%) \ldots .$. Vomiting 1 case $(2.50 \%) \ldots \ldots$ Shivering 1case $(2.50 \%)$
-Hypotension treated by $6 \mathrm{mg}$ ephedrine and dose repeated as need; Bradycardia treated by $0.5 \mathrm{mg}$ atropine; Nausea and Vomiting treated by Meclopram ;Shivering treated by warming fluids and blankets.

In agreement to our study; Abdel-Halim 2011 in his study (the effect of single dose of magnesium sulfate or dexamethasone as adjuvant to local anesthesia); said that no significant difference between two group in incidence of complication

Also ;In agreement to our study; Nair et al 2103 in their study (Clinical effects of intrathecal midazolam versus intrathecal magnesium sulfate as adjunct to hyperbaric bupivacaine) ; found that in the magnesium sulfate group four patients had nausea and two patients experienced vomiting. Other adverse e ects like pruritus and urinary retention were not seen in any of the study groups. Also no significant hemodynamic side e ects with intrathecal midazolam or magnesium sulfate

\section{Conclusion}

In conclusion, the addition of Dexamethasone $4 \mathrm{mg}$ or Magnesium Sulphate $50 \mathrm{mg}$ to intrathecally injected Bupivacaine improved the effect of Bupivacaine and the postoperative analgesic effect and duration without serious significant changes in patients' hemodynamics and without serious complications when certain safety measures were taken.

\section{References}

1- Bani-Hashem N, Hassan-Nasab B, Pour EA, Maleh PA, Nabavi A, Jabbari A. Addition of intrathecal dexamethasone to bupivacaine for spinal anesthesia in orthopedic 
surgery. Saudi J Anaesth 2011; 5:382386.

2- BROMAGE P.R.: An evaluation of bupivacaine in epidural analgesia for obstetrics. Can. Anesth. Soc. J., 16: 46-56, 1969. Coated from Jaiswal P., Ranjan N., Tewari N., Agrawal R., Mathur S.K.: Comparative study of epidural midazolam and butorphanol as adjuvant with bupivacaine for labor analgesia: A double blind study. The Intenret Journal of Anesthesiology, Vol 14 Number 1, 2007.

3- BUVANENDRAN A., MCCARTHY R.J., KROIN J.S., LEONG W., PERRY P. and TUMAN K.J.: Intrathecal magnesium prolongs fentanyl analgesia: A prospective, randomized, controlled trial. Anesth. Analg., 95: 661-6, 2002.

4- Gupta R, Bogra J, Verma R, Kohli M, Kushwaha JK, Kumar S. Dexmedetomidine as an intrathecal adjuvant for postoperative analgesia. Indian J Anaesth 2011; 55:347351.

5- Hisham Ahmed Fouad, Amal Mohammed Sabry Ahmed, Yasser
Mohammed Mohammed Osman and Gamal Mohammed Taha Abouelmagd, Efficacy of primitive Dexamethasone added to Bupivacaine in ultrasound guided transverses abdominis plain block for POSTOPERATIVE analgesia after inguinal herniorrraphy. American Journal of Research Communication 2016

6- Movafegh A, Razazian M, Hajimaohamadi F, Meysamie A. Dexamethasone added to lidocaine prolongs axillary brachial plexus blockade. Anesth Analg 2006; 102:263-267.

7- Sapna Shashni, Abhijit S. Nair, T V S Gopal. Clinical effects of intrathecal midazolam versus intrathecal magnesium sulfate as adjuncts to hyperbaric bupivacaine: A comparative study. Indian journal of pain .Jan 2014.

8- Soave PM, Conti G, Costa R, Arcangeli A. (2009): Magnesium anaesthesia. Curr Drug Targets; 10:734-43. 